\title{
Antigenic Relationships between Epidemic Strains and Vaccine Strains of Equine H3 Influenza Viruses
}

\author{
Armando Mario DAMIANI ${ }^{1}$, Yoshio FUKUNAGA ${ }^{2}$, Takeshi KUMANOMIDO ${ }^{2}$, Masanobu \\ KAMADA $^{2}$, and Hiroshi IMAGAWA ${ }^{2, *}$ \\ ${ }^{1}$ Department of Virology, Faculty of Veterinary Science, University of La Plata, La Plata, Argentina, and \\ ${ }^{2}$ Epizootic Research Station, Equine Research Institute, Japan Racing Association, Tochigi 329-04, Japan
}

To confirm whether influenza A/equine-2: $H 3 N 8$ viruses contained in vaccines presently available in Japan correspond to recent epidemic Alequine-2 viruses, the antigenic relationship between 12 epidemic strains (isolated in six countries from 1979 to 1993) and two Alequine-2 vaccine strains (A/equine/Tokyo/2/71 and equine/Kentucky/1/81) was studied by using guinea pig antisera against the vaccine strains and the serum from a vaccinated horse. Ten epidemic strains possessed close antigenicity to A/equine/Kentucky/1/81, but two strains (and possibly a third) isolated in England in 1979 and 1991 showed different antigenicity to A/equine/Kentucky/1/81. On the other hand, the antigenicity of all 12 epidemic strains was different from that of Alequine/Tokyo/2/71. These results suggest that strains which correspond to recent epidemic strains should be used as vaccine strains in order to ensure a higher level of prevention.

Key words: equine, influenza, vaccine

\author{
J. Equine Sci. \\ Vol. 6, No. 3 \\ pp. 73-78, 1995
}

According to epidemic data, influenza is one of the most serious viral respiratory diseases of horses in the world. Equine influenza viruses are classified as either A/equine-1: H7N7 or A/equine2: H3N8, according to antigenic differences in hemagglutinin and neuraminidase on the virion. A/equine-2 strains of influenza virus are divided into 2 major groups by gene and antigenic analysis. One is the prototype strain $\mathrm{A} /$ equine/Miami/63. The other one is originated from a avian influenza virus, and was isolated in a major epizootic which occurred among horses in northern China in 1989 and 1990 [4]. No new cases have been identified since 1990, thus it is suspected that this unusual virus failed to sustain itself within the equine population [8].

A/equine-1 strain has not been isolated since it was last isolated in Yugoslavia in 1980 [8]. However, antibody against A/equine-1 in unvac-

This article was submitted July 21, 1995, and was accepted October 1, 1995.

*corresponding author. cinated horses has been reported as recently as 1990 in Switzerland and the USA [8].

At present, viruses which have spread worldwide are all within the A/equine- 2 category. There have been repeated epidemics due to antigenic drift and genetic evolution [7]. A/equine-2 is endemic in the equine populations in Europe and North America [8]. However extensive outbreaks have occurred in South Africa in 1986 due to horses imported from the United States [10], and in India in 1987 [11] and in Hong Kong in 1992 [9] due to horses imported from Europe. Moreover a major A/equine/2 outbreak which affected more than one million horses occurred in China during 1993 and 1994 (Shortridge, personal communication).

In 1971, a severe influenza outbreak caused by A/equine- 2 occurred among horses in Japan [1], however, since then there have been no reoccurrences in the country. Since the number of horses imported into Japan has been increasing steadily in recent years, there is concern that imported 
horses might bring viruses into Japan. Since 1971, all racehorses and some riding horses have been inoculated with influenza vaccines routinely every year in Japan. The presently available vaccines in Japan are inactivated vaccines containing A/equine- 1 virus (A/equine/Newmarket/77) and A/equine-2 virus (A/equine/Tokyo/2/71 and $\mathrm{A} /$ equine/Kentucky/1/81). Since 1983 , these three strains have been used exclusively.

This paper describes the antigenic relationships between the two A/equine- 2 vaccine strains used in Japan and the recent A/equine-2 epidemic strains which have been isolated in Europe, the United States and Argentina.

\section{Materials and Methods}

Virus: The two vaccine strains and 12 isolated strains used in this study are shown in Table 1. The strains A/equine/Newmarket/D64/79, A/equine/Sussex/93753/89, A/equine/Arundel/12369/ 91, A/equine/Lambourn/22778/92, A/equine/Yvelines/2136/89, A/equine/Rome/5/91 and A/equine/ Cavrot $/ 87$ were obtained from $D$. Jessett, of the Animal Health Trust, Newmarket, England. The strains A/equine/Kentucky/90, A/equine/Kentucky/91 and A/equine/Kentucky/92 were supplied by T.M. Chambers, University of Kentucky, Kentucky, U.S.A. The strains A/equine/La Plata/85 and A/equine/La Plata/93 were obtained from E.O. Nosetto, University of La Plata, La Plata, Argentina. All strains used were obtained as

Table 1. Equine influenza virus strains used in this study

\begin{tabular}{lll}
\hline \multicolumn{1}{c}{ Strains } & Countries & Years \\
\hline Vaccine strains & & \\
Eq/Tokyo/2/71 & Japan & 1971 \\
Eq/Kentucky/1/81 & USA & 1981 \\
Epidemic strains & & \\
Eq/Newmarket/D64/79 & England & 1979 \\
Eq/Sussex/93753/89 & England & 1989 \\
Eq/Arundel/12369/91 & England & 1991 \\
Eq/Lambourn/22778/92 & England & 1992 \\
Eq/Yvelines/2136/89 & France & 1989 \\
Eq/Rome/5/91 & Italy & 1991 \\
Eq/Cavrot/87 & South Africa & 1987 \\
Eq/Kentucky/90 & USA & 1990 \\
Eq/Kentucky/91 & USA & 1991 \\
Eq/Kentucky/92 & USA & 1992 \\
Eq/La Plata/85 & Argentina & 1985 \\
Eq/La Plata $/ 93$ & Argentina & 1993 \\
\hline
\end{tabular}

viruses grown on embryonated hens eggs. They were used for serum neutralization (SN) and hemagglutination inhibition (HI) tests after they were passaged three or four times in Madin Darby Canine Kidney (MDCK) cells.

Serum neutralization test: $\mathrm{SN}$ test by plaque reduction was performed in $60-\mathrm{mm}$ plastic dishes of MDCK cell monolayers. Serial two-fold dilutions of test serum (heat-inactivated at $56^{\circ} \mathrm{C}$ for 30 min) were mixed with equal volumes of viral suspension containing about $100 \mathrm{pfu}$ per $0.2 \mathrm{ml}$. The mixture were kept at $37^{\circ} \mathrm{C}$ for $1 \mathrm{~h}$ for neutralization. A $0.4 \mathrm{ml}$ of mixture was inoculated into cells which had been previously cultured for 3 days. After incubation for $1 \mathrm{~h}$ at $37^{\circ} \mathrm{C}$, the cells were washed two times with $\mathrm{R}$ solution and received a $5 \mathrm{ml}$ agar overlay of Eagle minimum essential medium containing $2 \mu \mathrm{g} / \mathrm{ml}$ of acetyltryp$\sin$ (Sigma), $50 \mu \mathrm{g} / \mathrm{ml}$ of DEAE-dextran, $100 \mathrm{mg} / \mathrm{ml}$ of tryptose phosphate broth, $0.5 \mathrm{mg} / \mathrm{ml}$ of yeast extract, $1 \mathrm{mg} / \mathrm{ml}$ of glucose, $0.9 \mathrm{mg} / \mathrm{ml}$ of sodium bicarbonate, $4.8 \mathrm{mg} / \mathrm{ml}$ of purified agar (Difco), and antibiotics. The dishes were placed in a $\mathrm{CO}_{2}$ incubator for 3 to 4 days. After the overlay medium was removed, dishes were stained with a staining solution consisting of $1 \%$ crystal violet in $25 \%$ ethylalcohol for plaque observation. The SN antibody titers were expressed as reciprocals of the highest serum dilution causing a $60 \%$ reduction in the plaque counts.

HI test: An HI test was performed using the same methods described previously [6] except for antigen. Virus propagated in MDCK cells were used as the HA antigen. The antigen was not treated with Tween 80 and ether. HI antibody titers were expressed as reciprocals of the highest serum dilution which completely arrested hemaglutination.

Guinea pig immune serum: Culture fluids of A/equine/Tokyo/2/71 and A/equine/Kentucky/1/81 propagated in MDCK cells were ultra-centrifuged $(40,000 \mathrm{rpm}, 1 \mathrm{~h})$ whereupon the pellet was dissolved in a small volume of PBS. The suspended virus was purified by centrifugation $(40,000 \mathrm{rpm}, 1 \mathrm{~h})$ with a 10 to $30 \%$ sucrose density. The purified virus was mixed with Freunds complete adjuvant and was inoculated into the muscle of guinea pigs which were antibody free against each strain. Two and four weeks later after the first inoculation, these animals were twice inoculated intraperitoneally with the purified virus 
without adjuvant. They were bled in order to collect serum 1 week after the last inoculation.

Vaccinated horse serum: Commercial equine influenza inactivated vaccine (Nisseiken Co., Ltd., Tokyo) containing A/equine/Newmarket/l/77 (A/ equine-1) and A/equine/Tokyo/2/71 and $\mathrm{A} /$ equine/Kentucky/1/81 (A/equine-2) was injected into the muscle of a yearling horse which had not been previously vaccinated. One and 6 months later, the horse was revaccinated. Serum used was collected one month after the last inoculation.

\section{Results}

Antigenic relationships between the 12 epidemic strains and the two vaccine strains determined by HI test: The antigenic relationships between the 12 epidemic strains and the two vaccine strains are shown in Table 2. Except for A/equine/ Newmarket/D/64/79 and A/equine/Arundel/12369/ 91 the other 10 epidemic strains cross-reacted with either the same titer, or an 8-fold higher titer in comparison with the homologous titer of serum against A/equine/Kentucky/1/81. A/equine/Newmarket/D64/79 did not cross-react with serum to A/equine/Kentucky/1/81, however A/equine/ Arundel/12369/91 cross-reacted with a four-fold lower titer than the homologous titer. None of the 12 strains cross-reacted with serum to A/
equine/Tokyo/2/71.

Antigenic relaiionships between the 12 epidemic strains and the two vaccine strains determined by serum neutralization test: The antigenic relationships between the 12 epidemic strains and the two vaccine strains determined by the $\mathrm{SN}$ test are shown in Table 3. Except for A/equine/ Newmarket/D64/79, A/equine/Arundel/12369/91 and A/equine/Lambourn/22778/92 the other nine strains cross-reacted with antibody titers in a range 2-fold lower titers and 4-fold higher titers in comparison with the homologous titer of A/equine/Kentucky/81. A/equine/Newmarket/D64/ 79, A/equine/Arundel/12369/91 and A/equine/ Lambourn/22778/92 cross-reacted with a 4 - to 16 fold lower titers in comparison with the homologous titer of $\mathrm{A} /$ equine/Kentucky/1/81.

On the other hand, all 12 epidemic strains crossreacted with a 4 to 32 fold lower titer in comparison with the homologous titer of $\mathrm{A} /$ equine/Tokyo/71.

SN antibody titers against the 12 epidemic strains in serum of a horse inoculated with inactivated vaccine: The SN antibody titers against 12 epidemic strains in the serum of a horse inoculated with inactivated vaccine are shown in Table 4 . Except for $\mathrm{A} /$ equine/Newmarket/D64/79 and A/equine/Arundel/12369/91 antibody titers against the other 10

Table 2. Antigenic relationships among H3N8 equine influenza virus strains by the haemagglutination inhibition test

\begin{tabular}{|c|c|c|c|}
\hline \multirow{2}{*}{ Strains } & \multirow{2}{*}{ Countries } & \multicolumn{2}{|c|}{$\begin{array}{c}\text { HI titers with guinea pig } \\
\text { antisera to }\end{array}$} \\
\hline & & $\mathrm{Eq} /$ Kentucky/1/81 & $\mathrm{Eq} / \Gamma$ okyo/2/71 \\
\hline Eq/Kentucky/1/81 & USA & 128 & $<8$ \\
\hline $\mathrm{Eq} / \mathrm{Tokyo} / 2 / 71$ & Japan & 16 & 256 \\
\hline Eq/Newmarket/D64/79 & England & $<8$ & $<8$ \\
\hline $\mathrm{Eq} /$ Sussex $/ 93753 / 89$ & England & 256 & $<8$ \\
\hline $\mathrm{Eq} /$ Arundel/12369/91 & England & 32 & $<8$ \\
\hline Eq/Lambourn/22778/92 & England & 256 & $<8$ \\
\hline Eq/Yvelines/2136/89 & France & 128 & $<8$ \\
\hline Eq/Rome/5/91 & Italy & 512 & $<8$ \\
\hline $\mathrm{Eq} /$ Carrot $/ 87$ & South Africa & 128 & $<8$ \\
\hline Eq/Kentucky/90 & USA & 256 & $<8$ \\
\hline Eq/Kentucky/9l & USA & 1024 & 8 \\
\hline $\mathrm{Eq} /$ Kentucky/92 & USA & 512 & $<8$ \\
\hline Eq/La Plata/85 & Argentina & 256 & $<8$ \\
\hline $\mathrm{Eq} / \mathrm{La}$ Plata/93 & Argentina & 512 & $<8$ \\
\hline
\end{tabular}

Values in homologous reactions are in italics. 
Table 3. Antigenic relationships among H3N8 equine influenza virus strains by the plaque reduction neutralization test

\begin{tabular}{|c|c|c|c|}
\hline \multirow{2}{*}{ Strains } & \multirow{2}{*}{ Countries } & \multicolumn{2}{|c|}{$\begin{array}{l}\text { Serum neutralization titers with } \\
\text { guinea pig antisera to }\end{array}$} \\
\hline & & Eq/Kentucky/l/81 & Eq/Tokyo/2/7 l \\
\hline Eq/Kentucky 1/81 & USA & 16384 & 512 \\
\hline $\mathrm{Eq} /$ Tokyo/2/71 & Japan & 512 & 2048 \\
\hline Eq/Newmarket/D64/79 & England & 2048 & $\overline{128}$ \\
\hline Eq/Sussex/93753/89 & England & 16384 & 128 \\
\hline $\mathrm{Eq} /$ Arundel/12369/91 & England & 1024 & 128 \\
\hline Eq/Lambourn/22778/92 & England & 4096 & 256 \\
\hline Eq/Yvelines/2136/89 & France & 16384 & 128 \\
\hline Eq/Rome/5/91 & Italy & 16384 & 512 \\
\hline $\mathrm{Eq} /$ Cavrot/87 & South Africa & 16384 & 512 \\
\hline Eq/Kentucky/90 & USA & 8192 & 256 \\
\hline Eq/Kentucky/91 & USA & 32768 & 512 \\
\hline Eq/kentucky/92 & USA & 16384 & 256 \\
\hline Eq/La Plata/85 & Argentina & 32768 & 512 \\
\hline Eq/La Plata/93 & Argentina & 65536 & 64 \\
\hline
\end{tabular}

Values in homologous reactions are in italics.

Table 4. Serum neutralizing antibody titers of vaccinated horse serum against epidemic strains isolated at various countries

\begin{tabular}{llr}
\hline Strains & \multicolumn{1}{c}{ Countries } & SN titers \\
\hline Eq/Kentucky/1/81 & USA & $\frac{4096}{4096}$ \\
Eq/Tokyo/2/71 & Japan & $\frac{1024}{\text { Eq/Newmarket/D64/79 }}$ \\
Eq/Sussex/93753/89 & England & 16384 \\
Eq/Arundel/12369/91 & England & 1024 \\
Eq/Lambourn/22778/92 & England & 4096 \\
Eq/Yvelines/2136/89 & France & 4096 \\
Eq/Rome/5/91 & Italy & 8192 \\
Eq/Cavrot/87 & South Africa & 16384 \\
Eq/Kentucky/90 & USA & 4096 \\
Eq/kentucky/91 & USA & 16384 \\
Eq/Kentucky/92 & USA & 16384 \\
Eq/La Plata/85 & Argentina & 16384 \\
Eq/La Plata/93 & Argentina & 32768 \\
\hline
\end{tabular}

Titers against vaccine strains are in italics.

strains were the same, or 8-fold higher in comparison with antibody titers against A/equine/ Kentucky/1/81 and A/equine/Tokyo/71. Antibody titers against A/equine/Newmarket/D64/79 and $\mathrm{A} /$ equine/Arundel/12369/91 were 4 -fold lower in comparison with antibody titers against A/equine/Kentucky/1/81 and A/equine/Tokyo/2/ 71.

\section{Discussion}

It has been reported that genetic and antigenic variation has occurred among A/equine-2 viruses [2, 3, 5, 7]. Kawaoka et al. [7] reported that A/equine-2 viruses have evolved as a single lineage, with $\mathrm{A} / \mathrm{equine} / \mathrm{Miami} / 63$ as the starting point, and that clear antigenic drift occurred in about 1976. Viruses which had similar antigenicity to the variant virus apparently spreaded until 1987. In England, equine influenza occurred among horses inoculated with vaccine in 1989 according to Binns et al. [2]. The researchers showed the following results in their report: (1) A/equine/Suffolk/89 isolated during the epidemic possessed a partially different epitope in comparison with strains (A/equine/Miami/63 and A/equine/Fontainebleau/79) contained in current vaccines, (2) in an amino acid sequence of A/equine/Suffolk/89 HA, the amino acid of at least four major antigenic sites had changed when compared to the sequences of two currently used vaccine strains, and (3) A/equine/Suffolk/89 was closely related genetically to A/equine/Kentucky/86 and A/equine/Kentucky/87, both of which are current epidemic strains in the U.S.A. Chambers et al. [3] reported that two related families which closely related to the A/equine/ Suffolk/89 have been in circulation in the U.S.A. since 1990. New inactivated vaccine containing 
A/equine/Suffolk/89 has already been produced by a vaccine maker in the Netherlands.

When using an equine influenza vaccine for preventive purposes it is important to confirm whether horses administered the vaccine will in fact be protected against infection when exposed to virus in the field. This can probably be decided by studying the antigenic relationships between vaccine strains and current epidemic strains.

In this study, the antigenic relationships between two A/equine/2 virus strains (A/equine/ Kentucky/1/81 and A/equine/Tokyo/2/71) contained in vaccines currently used in Japan and 12 currently epidemic strains were examined. The epidemic strains were collected from several countries and were examined using guinea pig antisera against the vaccine strains, and horse serum collected from a yearling administered a current Japanese influenza vaccine. Of the 12 strains isolated from 1979 to 1993 , all but $\mathrm{A} /$ equine/Newmarket/D64/79 and A/equine/Arundel/12369/91 closely cross-reacted with $\mathrm{A} /$ equine/Kentucky/1/81 during an HI assay, using guinea pig antisera. Except for A/equine/ Newmarket/D64/79, A/equine/Arundel/12369/91 and A/equine/Lambourn/22778/92 the other nine strains all cross-reacted with A/equine/Kentucky/81 during an SN test using guinea pig antisera. Similar antigenic relationships were also observed during an SN test with horse serum from a vaccinated yearling. From these results, it was suggested that at least nine of the epidemic strains are similar in antigenicity to A/equine/Kentucky/1/81, but that two or possibly three of the strains isolated in England may be antigenic variants. On the other hand, it was confirmed that the antigenicity of all 12 epidemic strains are different from that of A/equine/Tokyo/2/71.

There are two important concerns essential to the preventive administration of equine influenza vaccine. One is to make sure that horses administered the vaccines maintain adequate antibody levels, in order to counter infection. Available inactivated vaccines do not provide high enough antibody titers for horses, and single or even multiple inoculation do not provide for adequate antibody titers over long periods of time. The development of a new type of vaccine which can maintain a high antibody titer for a long time is clearly needed. The other essential concern is to select viruses which are suitable as vaccine candidates for currently circulating A/equine/2 strains. It was shown that the antigenicity of some epidemic strains used in this study is different from that of A/equine/Kentucky/81. Further studies including antigenic and genetic analysis are needed to select suitable vaccine strains.

\section{Acknowledgments}

Armand Mario Damiani is a research fellow supported by National Technology and Scientific Research Council (Conicet-Argentina) and by JICA to study equine infectious diseases in Japan. The authors wish to thank Dr. J. A. Mumford, of the Department of Infectious Deseases of Animal Health Trast in England, for advice to this study. Thanks are also due to Ms. K. Arakawa, for her technical assistance.

\section{References}

1. Akiyama, Y., Kumanomido, T., Hirasawa, T., Okuda, Y., and Tabuchi, E. 1972. Studies on outbreak of equine influenza in Japan in 1971-Condition of outbreak and investigation of hemagglutination inhibiting antibody. Exp. Rep. Equine Health Lab. 9: 10-28.

2. Binns, M.M., Daly, J.M., Chirnside, E.D., Mumford, J.A., Wood, J.M., Richards, C.M., and Daniels, R.S. 1993. Genetic and antigenic analysis of an equine influenza H3 isolate from the 1989 epidemic. Arch. Virol. 130: 33-43.

3. Chamber, T. M., Lai, A.C.K., Flanklin, K.M., and Powell D.G. 1994. Recent evolution of the haemagglutinin of equine- 2 influenza virus in the USA. pp. 175-180. In: Proc. 7th International Conference on Equine Infectious Deseases, Tokyo.

4. Guo, Y., Wang, M., Kawaoka, Y., Gorman, O., Ito, T., Saito, T., and Webster, R.G. 1992. Characterization of a new avian-like influenza A virus from horses in China. Virol. 188: 245-255.

5. Hinshaw, V.S., Naeve, C.W., Webster, R.G., Douglas, A.R., Skehel, J.J. and Bryans, J.T. 1983. Analysis of antigenic variation in equine 2 influenza A viruses. Bull. Wld. Hlth. Org. 61: 153-158. 
6. Imagawa, H., Fukunaga, Y., Kamada, M., Nanbu, M., and Kitamura, M. 1993. Distribution of $\mathrm{HI}$ antibody against 3 vaccine strains of equine influenza virus in light-breed horses in Japan. Jpn. J. Equine Sci. 4: 31-38.

7. Kawaoka, Y., William, J.B., and Webster, R.G. 1989. Evolution of the hemagglutinin of equine H3 influenza viruses. Virol. 169: 283-292.

8. Mumford, J., and Wood, J. 1993. WHO/OIE Meeting: Consultation on newly emerging strains of equine influenza. Vaccine 11:
$1172-1175$.

9. Powell, D.G., Watkins, K.L., Li, P.H., and Shorridge, K.F. 1995. Outbreak of equine influenza among horses in Hong Kong during 1992. Vet. Rec, 27: 531-536.

10. Rogers, A.L. 1988. A-equine-2 influenza in horses in the Republic of South Africa. J. $S$. Afr. Vet. Med. Assoc. 59: 123-125.

11. Uppal, P. K., and Yadav, M. P. 1987. Outbreak of equine influenza in India. Vet. Rec. 121: 569-570. 